\title{
City Administration and Law Enforcement Officials' Work Stress: Evidences from Haidian District in Beijing
}

\author{
Ke Jianglin $^{1}$ Zhang Hanxi $^{2}$ Hu Jing-ming ${ }^{3}$ \\ 1 School of Management, Beijing Normal University, Beijing, P.R.China, 100875 \\ 2 School of Management, Beijing Normal University, Beijing, P.R.China, 100875 \\ 3 Bureau of Law Enforcement and City Administration, Haidian, Beijing, P.R.China \\ (E-mail: jingminghu1983@sina.com)
}

\begin{abstract}
Bureau of city administration and law enforcement is a special public department in China and its officials' important role is to maintain the city's order and beauty. In the work condition, they bear lots of work stress. Though work stress is a hot topic in recent years, the study on city administration and law enforcement officials is lack. Based on this, we surveyed city administration and law enforcement officials from Haidian district to study their work stress reactions, work stressors and management practices. According to 201 valid samples, we found that they have various stress reactions from stomach upset to frustration, and their stress reactions have significant correlation with stressors of social support, job-itself, living stress, learning stress, career development and special expenses.
\end{abstract}

Key word: City administration and law enforcement officials, Work stress, Stressor, Stress management

\section{Introduction}

Bureau of city administration and law enforcement is a special public department in China and mains to improve the insufficiency on multi-department law enforcement, which means it gets some power of penalty from some other departments and performs these powers. Since 1980s, we've been developing rapidly in economy and society, which increases and complicates the work affairs of city administration and law enforcement officials. However, the public opinion often criticizes them and the reports of the disputes and body conflicts between city administration and law enforcement officials and vendors appear a lot on the newspapers [1]. "Dispatching vendors, destroying unlawful buildings, cleaning up the city and being criticized or even beaten", this is the real life of city administration and law enforcement officials. In these disputes, people always think that vendors are the weak one and city administration and law enforcement officials are the strong one. And city administration and law enforcement officials have almost become the symbol of "violence" [2]. Actually, people neglect the fact that city administration and law enforcement officials also suffer. The difficulty of city administration and law enforcement officials' work makes them facing more and more stress, which not only makes them feel hurt, but also affects their work attitude and performance. Sometimes, this may even lead to people's dissatisfaction with the government. Therefore, we need to improve the city administration and law enforcement officials' work quality and efficiency for a higher satisfaction with the city management, which cannot be achieved under high stress.

However, though western management and psychology have paid much attention to work stress, the start of stress study is late in China and our study object are always centered on medical practitioners, teachers and guderians. Besides, the work stress of city administration and law enforcement officials has always been neglected for the particularity of their work and peoples' recognition deviation and few scholars in China have paid attention to city administration and law enforcement officials' work stress. As we have researched, only few people like Hongmin Chen (2010) [3] has referred to city administration and law enforcement officials' work stress. Since different occupations have different work stress reaction and work stressors [4] and occupations like medical practitioners and 
teachers differ a lot from city administration and law enforcement officials. We cannot just apply their stress management modes to these officials, it's essential to get an overall knowledge on city administration and law enforcement officials' work stress and work out a scheme of stress management.

\section{Literature Review}

\section{1. city administration and law enforcement officials}

The bureau of city administration and law enforcement is a comprehensive law enforcement department in China and it was first put forward in 1996 when "Administrative Penalties Law" was issued. Xuanwu district of Beijing founded the first law enforcement team of city administration in 1997[5] and then more and more cities founded their own ones. It functions mainly contains carrying out national and municipal laws and regulations about urban administration, controlling and maintaining urban administration order, organizing and drafting the municipal laws and regulations [6]. In general, city administration and law enforcement officials carry out the relatively centralized power of administrative penalties in 13 fields such as city appearance and environmental sanitation, city planning administration, industrial and commercial administration, municipal administration, public utilities [7].

In recent years, city administration and law enforcement officials and vendors often quarrel with each other and sometimes they even have body conflicts. However, the fact that city administration and law enforcement officials are also the victims and get hurt in the conflicts is often neglected. Just like Xin Liu, Ying Liu and Keyong Dong (2010) found in their study that this dilemma makes city administration and law enforcement officials have more and more work stress, which has a really bad influence on their mind and body and physical reactions like dizziness, nausea, and insomnia and emotional reactions like nerve stress and irritability become more and more common [8].

\subsection{Work stress}

"Stress" is used to describe the tension state psychologically and physically in people's work and living and comes from the field of psychology and engineering. In recent years, "stress" has got attention from many fields such as medical and sociology. In general, we can define it into three catalogue though they don't have a unified definition and nature. They are "work stress stimulation" by Caplan(1975) [9] and Copper (1976)[10], "work stress reaction" by Seley (1956) and the theory that combines the formers. In this article, we combine the above researches and adopt the definition by domestic scholar Yuling Bai (2010) [11], that work stress is a reactive process that threat the work behaviors as to make the individual feel a series of physical and psychological behaviors under the interaction between the individual and the environment in the work situation. Just like what Zhou Ju founded in "work burnout and stress management of civil servants", as the social competition and pressure become more and more common, civil servants including city administration and law enforcement officials suffer from more and more stress [12] .

\subsection{Work stressor}

Work stressor is external stimulate leading to work stress, which includes external incidents and environment. It can be an occurrence, or can be caused by progressive problem. The latter always is micro stressor and called daily struggle in academic (Kanner, Coyne, Schaefer\& Lazarus, 1981) [13], such as finishing work hard or dealing with tough customers every day. Kahn (1964), Weiss (1976) and Copper (1988) classified the work stressor according to different theories and objects. In general, they all include the stressors from the organization internals, organization externals and individuals [14]. Here, we classify it into 8 dimensions (social support, job-itself, personal relationship, living stress, learning stress, salary, career development and special expense).

\section{Method}

\subsection{Sample}

We surveyed the city administration and law enforcement officials of Haidian district in Beijing and handed out 240 questionnaires. In total, the valid sample number is 201. Male accounts for $80.5 \%$ and female is $19.5 \%$; $32 \%$ of them age from 31 to 40 and both the age from 18 to 30 and from 41 to 50 is $27.5 \%$; $64 \%$ have married and $49 \%$ of them have one child 
to bring up and the rest $39.5 \%$ have no child. Ones having the work experiences longer than 10 accounts for $35.5 \%$ and $29 \%$ from 1 to 3 years and $27 \%$ from 3 to 10 years; among the samples, $42.5 \%$ have a education background of college for professional training and $43 \%$ have bachelor's degree. As to the occupation, middle-level officials account for $43.5 \%$ and $49.5 \%$ are the ones below the middle-level, therefore, we can see that most of them have high occupations; the most $49.5 \%$ have a year salary of 50000 to 59000; those who work for over 10 hours every day accounts for $45.5 \%$ and $33.5 \%$ have a work hour between 8 to 10 , which means long working hours for city administration and law enforcement officials.

\subsection{Measures}

Since the domestic work stress scales and foreign ones differ a lot in development and use, we chose the "work stress questionnaire" developed by Mingliao Zhang [15] (2007) for the part of stress reactions and "work stress scale" developed by Yuanyuan Zhang's[16](2008) for the part of stressors and stress relief measures. The whole survey is based on our interviews with city administration and law enforcement officials and it contained 4 sections----background, work stress reactions, work stressors and improvement measures, counting for 71 items. All subjective variables' reliability is above 0.70(measured with Cronbach's $\alpha$ ).

\section{Analysis and Results}

\subsection{Stress reaction analysis}

In general, city administration and law enforcement officials of Haidian district have some physical and psychological reactions caused by work stress. As we can see in the table 1, more than $50 \%$ of the subjects have suffered from stomach upset, dizziness and insomnia; more than $30 \%$ have feelings like tiredness and tachypnea. Almost $90 \%$ of them always experience low spirits, impaired concentration, nervousness and irritability.

\begin{tabular}{|l|c|c|c|c|c|}
\hline & N & Minimum & Maximum & M & SD \\
\hline 1.stomach upset & 201 & 0 & 6 & 1.18 & 1.419 \\
2.tiredness & 201 & 0 & 6 & 1.58 & 1.636 \\
3.tachypnea & 201 & 0 & 6 & 1.28 & 1.349 \\
4.dizziness & 201 & 0 & 6 & 3.33 & .963 \\
5.insomnia & 201 & 0 & 6 & 3.83 & .952 \\
6.overeating, overdrinking and smoking & 201 & 0 & 6 & 3.74 & 1.232 \\
7.having low spirits at work & 201 & 0 & 6 & 4.19 & 1.278 \\
8.sometimes unable to concentrate & 201 & 0 & 6 & 3.99 & 1.150 \\
9.feeling nervous at work & 201 & 0 & 6 & 4.05 & 1.014 \\
10.having bad temper at work & 201 & 0 & 6 & 3.97 & 1.190 \\
11.irritability when with family & 201 & 0 & 6 & 4.35 & 1.168 \\
12.irritability when with coworkers & 201 & 0 & 6 & 3.67 & 1.443 \\
13.restlessness in working place & 201 & 0 & 6 & 3.88 & 1.281 \\
14.frustration when out of control of work & 201 & 0 & 6 & 3.81 & 1.182 \\
\hline
\end{tabular}

Tab.1: Stress reaction statistics

As for the frequency of the stress reaction (frequency increases from 0 to 6,0 means "never" and 6 means "everyday"), some malaises like stomach upset and respiration with a mean below 2 are't very strong, but emotional reactions are more frequent and strong and the most one is "irritability when with family" with a mean of 4.56 , next are "feeing nervous at work" and "having low spirits at work" with a mean over 4.0.

\subsection{Work stressor analysis}

Here, we analyzed the work stressors of city administration and law enforcement officials from 8 aspects like social support, work and personal relationship and each one has different sub-dimensions. We found that in social support dimension, "I always get discriminated for occupation and identity" has the highest mean of 4.20 (frequency increases from 0 to 6,0 means "never" and 6 means "everyday"); in job-itself, "position changes like promotion and demotion give me high stress" has the highest frequency and highest mean of 3.79; in personal relationship, "I'm well adapted to my leaders' work styles" gets the highest mean of 3.31; in living stress, "housing stress" gets the highest mean of 4.25; in salary, "I'm satisfied with the welfare" has the highest mean of 3.23; in career 
development, "I always have stress caused by achievements and reputations" gets the highest mean of 4.01 and in special expenses, "inter-relationships like weddings and funerals" gets the highest mean of 3.68.

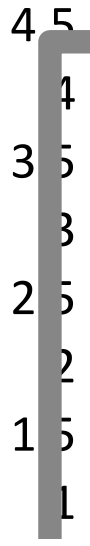

Figure 1: Work stressor dimensions comparison

\subsection{Correlation analysis of work stress reactions and work stressors}

Our study is based on Pearson's range correlation analysis and probe into the relationship among demographical variables,

Though correlation analysis, we found that stress reactions have significant correlation with the stressors like social support, job-itself, living stress, learning stress and career development at the level of 0.01 , with special expenses at the level of 0.05 and with no significant correlation with salary and personal relationship. As for the coefficients, social support is the highest with the number of 0.348 and the next highest are work and career development. Among the demography variables, work experiences is significantly correlated with stressors, while others like sex or age has no significant correlation with stressors.

Therefore, we can see that city administration and law enforcement officials have stress of different levels and 8 factors make up the main stressors, they are social support, living stress, learning stress, job-itself, personal relationship, career development, salary and special expenses. According to them, work stress factors and stressors. The results can be seen in table 2 .

the first 3 most powerful stressors are living stress, social support and job-itself. Based on the correlation analysis, stress reactions have significant correlation with stressors of social support, work, and living stress, learning stress, career development and special expenses and have insignificant correlation with salary and personal relationship. In demography variables, working hours is significantly correlated to work reactions.

4.4. Stress management analysis for city administration and law enforcement officials

We evaluated the subjects' recognition of 16 ways to relieve stress and these ways belong to government human resource management, organizational structure, personal relationship, practical activities and job-itself. The importance increases from 1 to 6 and 1 means "very unimportant" and 6 means "very important". The results can be seen in table 3 .

\begin{tabular}{lllll}
\hline \multicolumn{1}{c}{ Factor } & Mean & \multicolumn{1}{c}{ Measures } & Valid sample & Mean \\
\hline \multirow{2}{*}{$\begin{array}{l}\text { Government human } \\
\text { resource } \\
\text { management }\end{array}$} & 3.83 & 201 & 2.65 \\
\cline { 2 - 4 } & & Salary improvement & 201 & 2.58 \\
\cline { 2 - 4 } & & Porking condition improvement & 201 & 4.94 \\
\cline { 2 - 4 } & & Position information & 201 & 4.40 \\
\cline { 2 - 4 } & & Training plan & 201 & 4.62 \\
\hline
\end{tabular}




\begin{tabular}{lllll}
\hline $\begin{array}{l}\text { Organizational } \\
\text { structure and } \\
\text { leadership }\end{array}$ & 4.80 & Policy participation & 201 & 4.60 \\
\cline { 3 - 5 } & & Support from leaders & 201 & 5.03 \\
\cline { 3 - 5 } $\begin{array}{l}\text { Personal } \\
\text { relationship }\end{array}$ & Respects from organization & 201 & 4.77 \\
\hline \multirow{3}{*}{ Practical activities } & 4.74 & $\begin{array}{l}\text { Personal relationship } \\
\text { improvement }\end{array}$ & 201 & 4.74 \\
\hline \multirow{3}{*}{ Job-itself } & \multirow{2}{*}{4.85} & Organizational activities & 201 & 4.69 \\
\cline { 3 - 5 } & & Psychological counseling & 201 & 4.94 \\
\cline { 3 - 5 } & \multirow{2}{*}{4.91} & Stress recognition education & 201 & 4.93 \\
\cline { 3 - 5 } & & Relief of work strength & 201 & 4.90 \\
\cline { 3 - 5 } & & Enrichment of work content & 201 & 4.81 \\
\cline { 3 - 5 } & & Position change duly & 201 & 4.98 \\
\cline { 3 - 5 } & & Set-up of realizable goals & 201 & 4.96 \\
\hline
\end{tabular}

Table 3: Comparison of stress management measures

Measures with highest means are support from leaders of 5.03, position change duly of 4.98 and set-up of realizable goals of 4.96. As for the mean of 5 factors, the first three with the highest importance city administration and law enforcement officials assumed are job-itself(4.91), practical activities(4.85), organizational structure and leadership(4.80), personal relationship(4.74) and government human resource management(3.83). Based on these, improving the work itself can significantly relieve the city administration and law enforcement officials' stress and this includes relieving work strength, enriching work contents, changing positions duly and setting up realizable goals. And next significant factor is organizing different practical activities. We can see this in Figure 2.

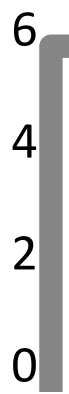

Figure 2: Comparison of stress management factors

According to these, we suggest to carry out city administration and law enforcement officials' stress management from two levels---organizational one and individual one.

From the organizational level, work itself has become the second main stressor of city administration and law enforcement officials' stress for their work's huge tasks, complicated contents and uncertainty. As for the relief measures, the relief of the job itself is very important for them, therefore, carrying out job analysis is important for improving work stress. As long as the city administration and law enforcement officials have a clear recognition of their work, they can avoid the stress caused by role ambiguity and role conflicts [17]. On the other hand, establishing clear career development, strengthening social recognition of city administration and law enforcement officials' law enforcement and establishing psychological counseling can also enhance the management of city administration and law enforcement officials' work stress.

Work stress management is not only the obligation of organization, but also the obligation of the individuals. From the individual aspect, city administration and law enforcement officials can establish correct self-recognition, developing healthy work habits, managing self-emotions, enlarging the support net from the social and relaxing physically for work stress relief.

\section{Conclusion and suggestions}

\subsection{Conclusion}

Our research is concentrated on the city administration and law enforcement officials' 
work stress and combined with the reviews and empirical research, we get the following conclusions: (1) in general, city administration and law enforcement officials investigated have suffered from physical and psychological reactions caused by work stress; (2) the stressors of city administration and law enforcement officials include social support, job-itself, personal relationship, living stress, learning stress, salary, career development and special expenses; (3) work experiences is closely related to the stress reactions and the longer they work, more stress they will burden and more obvious the stress reactions are; (4) according to correlation analysis, stress reactions are significantly correlated to social support, job-itself, living stress, learning stress, career development and special expenses and have no significant correlation with salary and personal relationship; (5) the most important ways to relieve work stress for city administration and law enforcement officials are job-itself, practical activities, organizational structure and leadership; (6) we should carry out stress management from both the organization aspect and individual one.

\subsection{Limitations and research suggestions}

Although we get some progress and development, the research still has some shortcomings: (1) the sample is only limited to the city administration and law enforcement officials of Haidian district of Beijing, causing both low quantity and narrow region; (2) we chose the subjective evaluation, which may has some deviation with the real situation and affects the conclusion's reliability.For the above shortcomings, we assume that the future research can be deepen in following aspects: (1) enlarge the research range and increase the sample; (2) draw in mediators like characteristics and stress strategy as buffer; (3) carry out longitudinal study, design questionnaire with higher reliability and validity and take the objective evaluation.

Acknowledgment: Funded by National Natural Science Foundation of China (No. 71102020) and the Ministry of education of Humanities and Social Sciences Fund of China (No. 10YJC630107)

\section{References}

[1]Tang Zhaoming, Li Dexin. Conflicts resolutions between law enforcement and city administration officials and the society[J]. Outlook, 2006, (39):28-29(In Chinese).

[2]Chen Wei. The law enforcement difficulty of law enforcement and city administration officials in governing vendors[J]. Legal System and Society, 2012, (07):200-201(In Chinese).

[3]Chen Hongmin, Zhao Lei, Liu Lixin. A Regulatory Effect of the Coping Strategies by Urban Management Enforcement Officials on the Relationship Between Their Sense of Pressure and Their Mental Health [J].Chinese Journal of Special Education, 2010, (03), 73-76 (In Chinese).

[4]Zhou Yueping, Zhou Lianying. Comparative Study on the Work and Life Stressors and Response[J]. Exploration and Psychology, 2004, (01):63-69 (In Chinese).

[5]Ma Huaide, Che Kexin. The Development Predicament of Comprehensive Law Enforcement of Beijing Municipal Administration and Its Solutions[J]. Administrative Law Review, 2008, (02):1-6 (In Chinese).

[6]Meng Zhaohui. Legality and value analysis to the comprehensive administrative enforcementin urban management: taking Beijing City for example[J]. Urban Problems, 2011,(06):76-80(In Chinese).

[7]Yu Zhihui.The survey of Chinese law enforcement and city administration officials[J]. Decision \& Information, 2011, (04):35-36(In Chinese).

[8]Liu Xin, Liu Ying, Dong Keyong. The Solution to the Dilemma of Integrative Law Enforcement in Municipal Administration from the View of Strategic Human Resource Management_-Taking Beijing as Research Target[J]. Journal of public management, 2010, 7(2):37-45(In Chinese).

[9]French J R P Jr,Caplan R D,Van Harrison R.The mechanisms of work stress and train[J].Chichester,England Wiley,1982,5-11.

[10] Cooper CL , Cooper RD, Eaker LH. Living with stress $[\mathrm{M}]$. London: Penguin Book s, 1988 .

[11] Bai yuling. The relationship between work stress, organizational support and work 
burnout[D]. Press of Capital University of Economics and Business, 2010 (In Chinese).

[12]Zhou Ju. Work burnout and stress management of civil servants[J]. Probe, 2007, (03):67-71(In Chinese).

[13]Shu Xiaobing, Liao Jianqiao. Research on Occupational Stress: An Analysis Framework--the Major Theories Of occupational Stress in the West [J]. Journal of Huazhong University of Science and Technology Edition of Social Sciences, 2002,(05):121-124 (In Chinese).

[14]Weiss M. Effects of work stress and social support on information systems management[M].1976.

[15]Zhang Mingliao. Research on Banking Executives of Financial Holdings Companies in Taiwan Area with Relation to Their Stress at Work, Work Fatigue, and Response Strategies[D]. Soochow University Press, 2007(In Chinese).

[16]Zhang Yuanyuan. The empirical study of local-level civil servants' work stress and stress management[D]. Capital University of Economics and Business Press, 2008(In Chinese).

[17]Zhu Yanyan.China's Civil Servants Research on Work Stress Management[D]. Inner Mongolia University Press, 2010(In Chinese). 


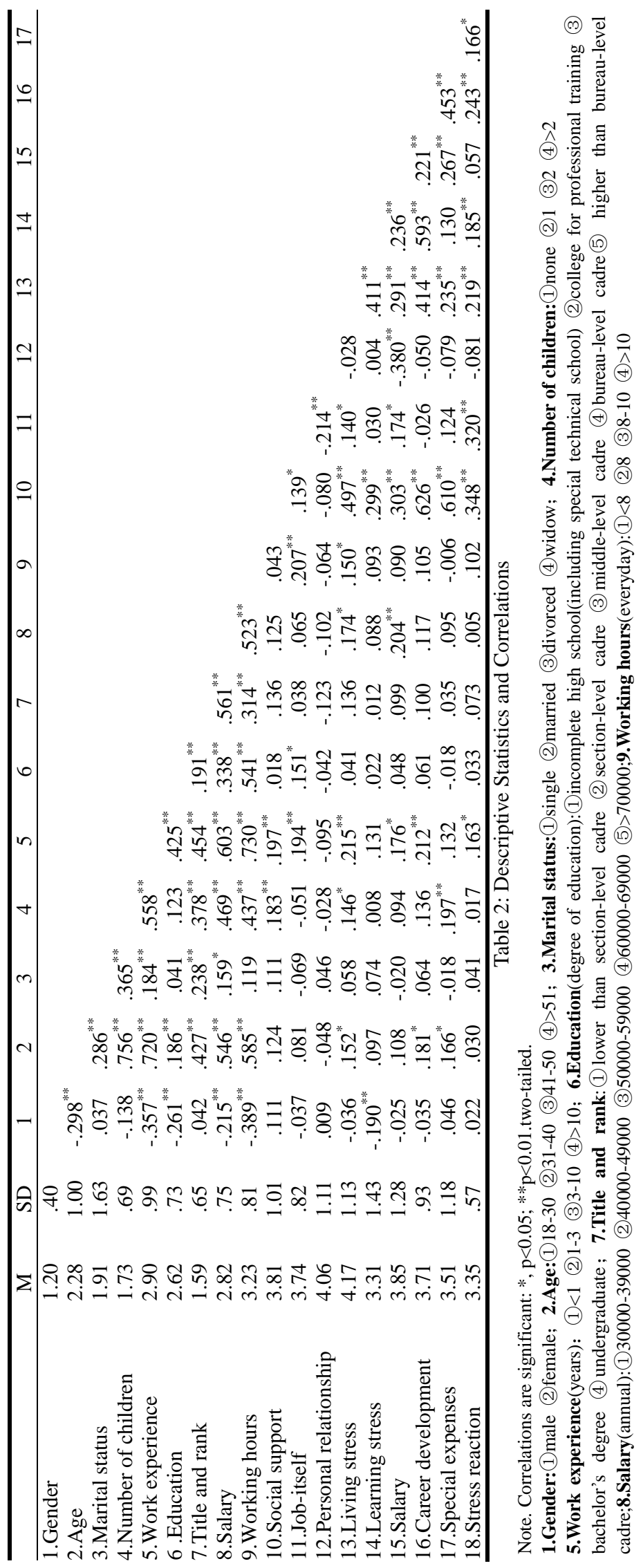

